\title{
New Concepts in the Management of Ptosis
}

\author{
J. R. O. COLLIN \\ London
}

\begin{abstract}
Summary
New concepts affecting congenital, Marcus Gunn jaw-winking, and involutional ptosis are discussed. A surgical technique for saving Muller's muscle is described. Recent studies of the histopathological changes in Marcus Gunn jaw winking ptosis and involutional ptosis are reviewed and the implications for surgery in these conditions presented.
\end{abstract}

New concepts in the management of ptosis have been based on a better understanding of the pathophysiology in different types of ptosis. This particularly affects the management of three different types: congenital, Marcus Gunn jaw-winking and involutional (senile) ptosis.

The commonest cause of congenital ptosis is a simple dystrophy of the levator muscle. Berke and Wadsworth ${ }^{1}$ showed that in patients with congenital ptosis due to a dystrophy of the levator palpebrae superioris muscle, there was a relationship between the levator muscle function and the number of striated muscle fibres in the levator muscle. Berke $^{2}$ and Beard ${ }^{3}$ produced tables suggesting the amount of levator muscle that should be resected to correct the ptosis based on a preoperative assessment of the levator function and the lid height achieved at operation. The classical techniques for a levator resection involve excising the aponeurosis and Muller's muscle with varying amounts of the levator muscle. Berke and Wadsworth ${ }^{1}$ did not find any abnormality in Muller's muscle in patients with ptosis; it therefore seemed a pity to excise this muscle unnecessarily and various techniques have been described for attempting to preserve it. Jones ${ }^{4}$ cut the levator muscle above Whitnall's ligament and advanced it to the tarsus but most surgeons have found difficulty in getting predictable results with this technique. Mustarde ${ }^{5}$ thought that the nerve supply to Muller's muscle travelled with the nerve to the levator muscle and that if the latter was cut, Muller's muscle would be denervated. He therefore tucked the levator muscle above Whitnall's ligament but this did not seem to produce better results than Jones' procedure. In 1975 Mustarde $^{6}$ described a split-level lid resection with inversion of Muller's muscle if necessary. The splitlevel lid resection removed orbicularis muscle and tarsal plate, and Muller's muscle was preserved without cutting the levator muscle. Technically this procedure is not easy and the tarsal plate excision can cause problems, particularly if any further lid surgery is required to adjust the eyelid contour or height. Collin, Beard and Wood ${ }^{7}$ showed that Muller's muscle was not denervated by cutting the levator muscle. They therefore modified Jones' operation by dividing the levator muscle above Whitnall's ligament and advancing it as he had done, but in addition they sutured the distal end of the cut levator muscle to the underside of the advanced levator muscle ${ }^{8}$ (Fig. 1). This preserved some tension in Muller's muscle and the aponeurosis and therefore maintained their function better than with Jones' procedure but it is technically difficult to place the high sutures. The preservation of Whitnall's ligament in this procedure makes a difference to the lid height

Correspondence to: J. R. O. Collin, FRCS, Moorfields Eye Hospital, City Road, London, EC1. 

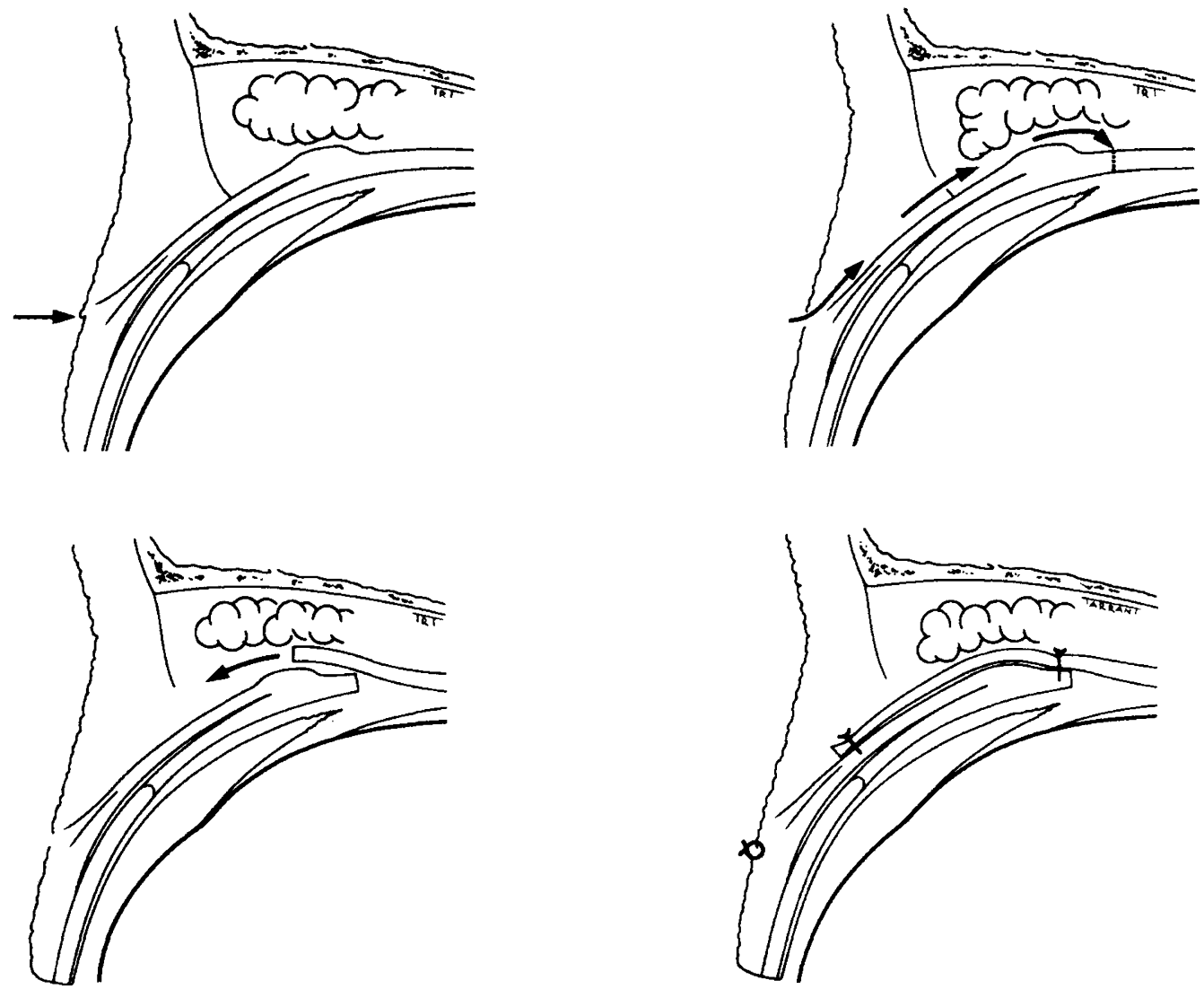

Fig. 1. Collin-Beard ptosis operation (Read figures left to right. For details see text)

but it is doubtful whether this applies to Muller's muscle and the aponeurosis. The main benefit of preserving Muller's muscle is probably not a raised eyelid level in the normal primary position of gaze, but the maintenance of the subtle changes in eyelid height and skin crease depth etc. associated with emotion, wakefulness and other autonomically mediated markers of facial expression.

A standard anterior approach levator resection $^{9}$ can easily be modified to preserve Muller's muscle (Fig. 2). The aponeurosis and Muller's muscle are identified but instead of dissecting Muller's muscle off the conjunctiva, the post-aponeurotic space is followed for $10 \mathrm{~mm}$ above the tarsus, and Muller's muscle is divided at this point. The aponeurosis and levator muscle can then be advanced under Whitnall's ligament and the same amount resected as one would have if Muller's muscle was also being excised at the same time. The skin crease is then reformed. Post-operatively if a sympathomimetic drug is instilled into the conjunctival sac in a patient in whom Muller's muscle has been preserved in this way, the eyelid elevates showing that Muller's muscle is indeed capable of functioning. The muscle probably adheres to the underside of the advanced levator muscle but its effectiveness may also depend on maintaining the 'common sheath' between the levator muscle and the superior rectus mucle and its forward extension, the superior ligament of the fornix.

The management of Marcus Gunn jawwinking ptosis is another area in which new concepts have been applied. If the abnormal 

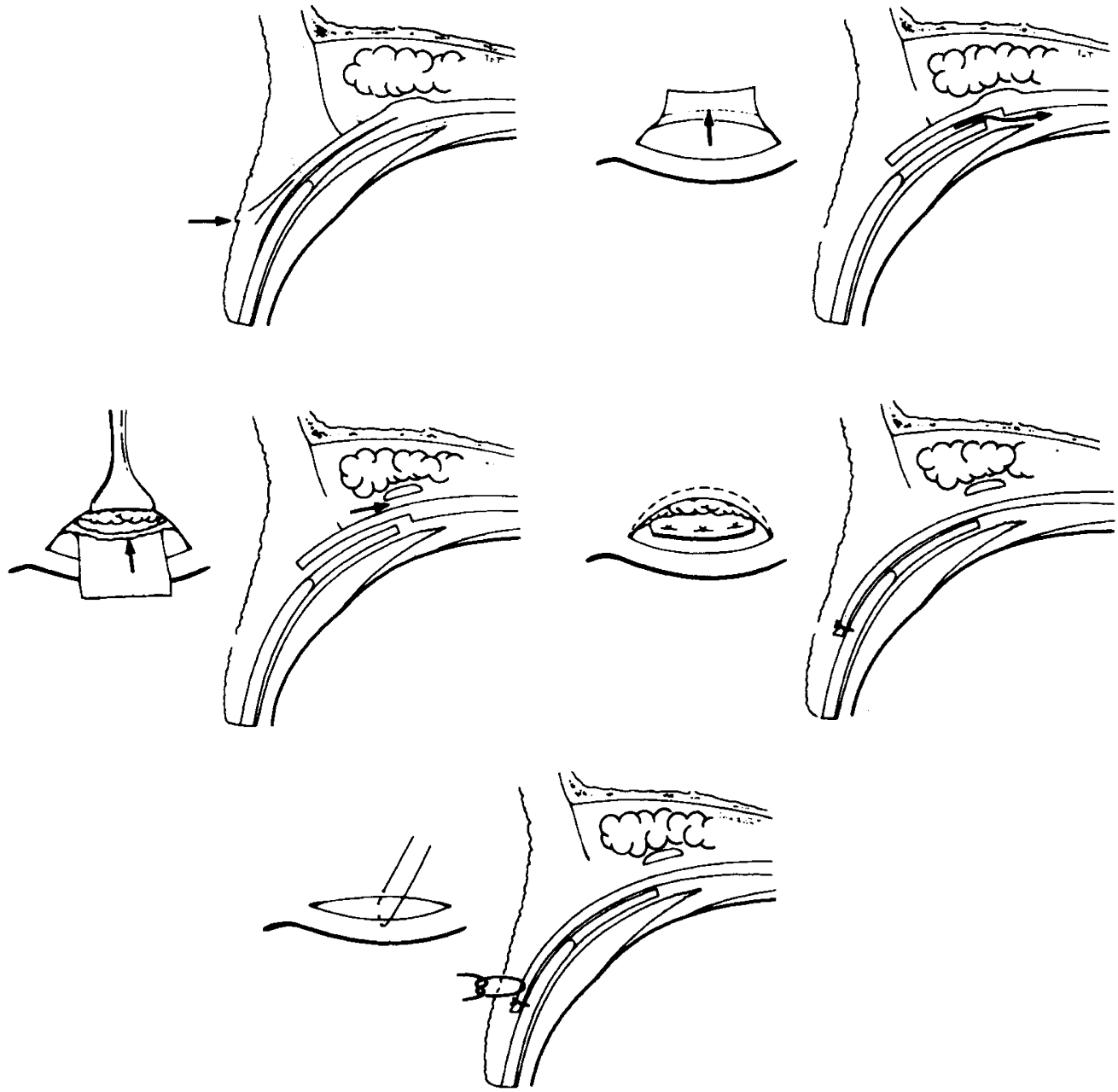

Fig. 2. Anterior approach levator resection saving Muller's muscle. (Read figures left to right. For details see text)

eyelid movement or wink is severe the usual management has been to excise a large part of the levator muscle in an attempt to abolish the aberrant movement and then to suspend the eyelid from the frontalis muscle with a brow suspension procedure. Lemagne ${ }^{10}$ first showed that instead of discarding the levator muscle, it could be cut as far back in the orbit as possible to abolish the wink. If its distal end was left intact, the transposed levator muscle could be used to suspend the eyelid from the frontalis muscle. He also showed that the muscle could even possibly obtain a new nerve supply by neurotisation from the frontalis muscle. This operation can work but its suc- cess will depend on the state of the levator muscle. A recent study ${ }^{11}$ of the pathophysiology of the levator muscle in patients with the Marcus Gunn jaw-winking phenomenon has shown variable fibrosis in the levator muscle; clearly any contractility that a transplanted muscle develops as a result of the neurotisation will be governed by the extent of the fibrosis already present in the muscle. This study also interestingly showed that pathological changes were present in both levator muscles. In patients with a jaw-wink and poor levator function therefore, a levator muscle excision and brow suspension procedure probably still remains the procedure of 
choice. Beard ${ }^{12}$ suggested that a bilateral levator excision and brow suspension procedure gives a more symmetrical and physiologically acceptable result than a unilateral procedure in these patients. The fact that the apparently 'normal' side is histologically abnormal may make it easier for parents and patients to accept the concept of Beard's bilateral procedure. $^{12}$

In 1976 Jones, Quickert and Wobig ${ }^{13}$ described aponeurotic defects as a cause of ptosis and since then a weakness of the aponeurosis has been generally accepted as the cause of involutional or senile ptosis. However a recent study of patients with involutional ptosis ${ }^{14}$ showed that although about 90 per cent of patients did have an aponeurotic weakness, the other 10 per cent had a normal looking aponeurosis and a marked fatty degeneration of the anterior levator muscle. The features of a pure aponeurotic weakness were a ptosis with good levator function, a raised skin crease and a thin lid, whereas those with fatty degenerative changes in the anterior levator muscle tended to have a ptosis with somewhat bulky lids, a normal skin crease, somewhat reduced levator function, a lateral shift of the tarsus, and a reduced tear film. It is not clear whether these represent two separate entities of involutional ptosis or just extremes of a spectrum. It is important to try to identify the small group of patients with a fatty levator muscle since their lid level should be set lower at surgery to compensate for the poor tear film. They need to be warned that post-operative lid oedema may last for a long time. At surgery the levator complex should be moved medially to compensate for any lateral tarsal shift or 'temporal peaking' of the lid may result.

This paper reviews new concepts affecting congenital, Marcus Gunn and involutional ptosis. These are based on a better under- standing of the anatomy and function of the upper lid retractors and careful analysis of the pathological changes which occur in these retractors to cause ptosis. It is hoped that an understanding of these new concepts will reduce some of the variability in the results of ptosis surgery.

\section{References}

' Berke RN and Wadsworth JAC: Histology of levator muscle in congenital and acquired ptosis. Arch Ophthalmol 1955, 53: 413-28.

${ }^{2}$ Berke RN: Results of resection of the levator muscle through a skin incision in congenital ptosis. Arch Ophthalmol 1959, 61: 177-201.

${ }^{3}$ Beard C: The surgical treatment of blepharoptosis: a quantitative approach. Trans Am Ophthalmol Soc 1966, 64: 401-87.

4 Jones LT: The anatomy of the upper eyelid and its relation to ptosis surgery. Am J Ophthalmol 1964, 57: 943-59.

${ }_{5}^{5}$ Mustardé JC: Experience in ptosis correction. Trans Acad Ophthalmol Otolaryngol 1968, 72: 173-85.

${ }^{6}$ Mustardé JC: Problems and possibilities in ptosis surgery. Plast and Reconstr Surg 1975, 56: 381-8.

${ }^{7}$ Collin JRO, Beard C, Wood I: Terminal course of nerve supply to Muller's muscle in the Rhesus monkey and its clinical significance. Am J Ophthalmol 1979, 87: 234-46.

${ }^{8}$ Beard C: Ptosis 3rd ed. St. Louis. CV Mosby, 1981: 191-2.

${ }^{9}$ Collin JRO: A manual of systematic eyelid surgery. Edinburgh. Churchill Livingstone, 1983: 51-56.

${ }^{10}$ Lemagne JM, Brucher JM, Michiels J: Clinical biochemical, and histological results of a levator muscle transposition for ptosis in cynomolgus monkeys. Orbit 1985, 4: 141-6.

"Lyness RW, Collin JRO, Alexander RA, Garner A: The histological appearances of the levator palpebrae superioris muscle in the Marcus Gunn phenomenon. BrJ Ophthalmol (In Press).

12 Beard C: A new treatment for severe unilateral ptosis and for ptosis with jaw-wink. Am J Ophthalmol 1965, 59: 252-8.

13 Jones LT, Quickert MH, Wobig JL: The cure of ptosis by aponeurotic repair. Arch Ophthalmol 1975, 93: 629-34.

${ }^{14}$ Collin JRO: Involutional Ptosis. Astral and New Zeal J Ophthalmol 1986, 14: 109-12. 